\title{
Typification of the binomial Sedum boissierianum Hausskncht Crassulaceae
}

\author{
V. Bârcă
}

Bârcă V., 2016. Typification of the binomial Sedum boissierianum Hausskncht Crassulaceae. Ann. For. Res. 59(1): 165-171.

Abstract. Genus Sedum, described by Linne in 1753, a polyphyletic genus of flowering plants in the family Crassulaceae, was extensively studied both by scholars and succulents enthusiasts. Despite the great attention it has received over time, many binomials lack types and consistent taxonomic treatments. My currently undergoing process of the comprehensive revision of the genus Sedum in România and the Balkans called for the clarification of taxonomical status and typification of several basionyms described based on plants collected from the Balkans and the region around the Black Sea. Almost a century and a half ago, Haussknecht intensely studied flora of Near East and assigned several binomials to plants of the genus Sedum, some of which were neglected and forgotten although they represent interesting taxa. The binomial Sedum boissierianum Haussknecht first appeared in schedae as nomen nudum around 1892, for specimens originating from Near East, but was later validated by Froederstroem in 1932. Following extensive revision of the relevant literature and herbarium specimens, I located original material for this taxon in several herbaria in Europe (BUCF, LD, $\mathrm{P}, \mathrm{Z})$. I hereby designate the lectotype and isolectotypes for this basionym and furthermore provide pictures of the herbarium specimens and pinpoint on a map the original collections sites for the designated types.

Keywords lectotypification, Sedum boissierianum Hskn, Sedum rubens L, Sedum hispanicum L, Crassulaceae, Near East, taxonomy

Authors. Valentin Bârcă (valentinbarca@yahoo.com) - "Carol Davila” University of Medicine and Farmacy- Bucharest, AGAVE HIIQ Solutions- Bucharest, Romania.

Manuscript received June 24, 2015; revised November 26, 2015; accepted December 10, 2015; online first January 29, 2016. 


\section{Introduction}

Genus Sedum, described by Linne in (1753:430), and in Linne (1754:197), is a polyphyletic genus of flowering plants in the family Crassulaceae, incorporating succulent plants distributed all over the world, from the sea level up to the high peaks in Mexico, South America and the Himalayas. Especially during the last century, it was extensively studied by scholars and succulents enthusiasts alike, including the species occurring in the Carpathian Mountains (Niculae \& Bârcă 2005, 2006). Despite the great attention it has received over time, many binomials lack types and consistent taxonomic treatments.

My currently undergoing process of the comprehensive revision of the genus Sedum in România and the Balkans called for the clarification of taxonomical status and typification of several basionyms described based on plants collected from the Balkans and the region around the Black Sea.

Almost a century and a half ago, Karl Heinrich Haussknecht, (1838-1903) intensely studied flora of Near East and assigned several binomials to Sedum plants, some of which were neglected and forgotten although they represent interesting taxa.

The binomial Sedum Boissierianum Haussknecht is a basionym that first appeared as handwritten name on the labels of several herbarium sheets bearing plants collected by P. Sintenis, one of the Sintenis brothers, in the last quarter of the 19'th century during his botanical travels in the Balkans and the Near East. Therefore, as it does not fulfill the mandatory requirements for effective publication, it must have been considered legally an unpublished nomen nudum.

In his 1932 monumental revision of the genus Sedum, Froederstroem (1932) validated the original name put forth by Haussknecht for specimens originating from Near East, providing diagnostic drawings accompanied by descriptive captions for specimens from
Northern Turkey. Froederstrom (1932 p75) mentions Sedum boissierianum Haussknecht as synonym to $S$. rubens L ( "S. boissierianum Hausskn. In herb.") thus validating Haussknecht's basionym, and providing a first known text description (see further herein).

Paul Ernst Emil Sintenis (1847-1907) with the abbreviated botanical name Sint, was a German pharmacist and plant collector from Seidenberg (Niederschlesien), who studied pharmacy in Breslau (1877-1879) before becoming a freelance expeditionary plant collector. He participated between 1872-1876 to his first biological collecting expedition in the Dobrogea area of Romania and Bulgaria (then under The Ottoman Empire) with his brother M.B.G. Sintenis. After this first expedition during which he helped collecting plants but also, mainly mammals and birds, he apparently got so much interested in this activity that he spent the rest of his professional life collecting plants away from both his homeland and his primary profession of pharmacist.

Paul Sintenis was more a professional collector than a scientist, and didn't published scientific materials about the plants he collected, instead sharing his extremely rich and diverse plant material with several scientists who described many novelties based on the specimens collected by P. Sintenis. Besides P. Sintenis' main collection comprising about 100000 specimens that according to Vegter (1986) is housed in the herbarium in Lund, Sweden LD, many duplicates that he often collected were distributed in herbaria across the world. According to Baytop (2010) amongst the botanists who studied specimens collected by Sintenis, the foremost were: J.F. Freyn (1845-1903), J.F.N. Bornmuller, H.C. Haussknecht and P.F.A. Ascherson (1834-1913).

He visited Turkey several times and collected plants during six expeditions to Anatolia and European Turkey between 1883 and 1894. In 1889 , he made a third expedition to Anatolia. He arrived at Trabzon at the beginning of April, collected within the provinces of 
Trabzon, Gümüshane, Erzincan, Malatya and Elazig (depicted on the map in Figure 1a, b), and returned from Trabzon at about mid-August. His collection from this trip comprises at least 1726 specimens (Cullen 1963 ex Baytop 2010) amongst which is the specimen seen by Froederstroem and currently housed in LD.

In 1892, he landed at Inebolu (N. Anatolia) in April, went up to Tossia via Küre and Kastamonu (same map, Figure 1a, b), and returned to Inebolu after June 1992 with a collection numbering from 3660 to 5349 (Cullen 1963 ex Baytop 2010). From this trip date the specimen duplicates housed in the herbaria of ICAS Bucharest (BUCF) and the herbarium in Paris P.

A thorough comparative revision of the extant specimens of Sintenis's plant named by Haussknecht as $S$. boissierianum Hskn with the descriptions and available material of $S$. rubens $\mathrm{L}$ in the light of current generally accepted concept of $S$. rubens L (Forederstrom 1932, Hart 1991), - led me to the opinion that S. boissierianum Hskn is clearly not conspecific with $S$. rubens L. The text of description provided by Froederstroem under $S$. rubens L. refers to a group of several taxa that are clearly distinct in a variety of characters, so the necessity of designating a type for this basionym became obvious and constitutes the objective of this research.

\section{Material and methods}

This study is based on literature search and on my personal revision of the plant material housed in the following herbaria (CL, BVS, CRAI, CRAF, BUCA, BUC, BUCF, BUAG, IAGB M, KRA, PRM, MPU, A, MA, LD, $\mathrm{W}$ and $\mathrm{WU}$; the herbarium acronyms follow Index Herbariorum (Thiers 2012). I was not able to personally review the original material housed in Paris (P) and Zurich (Z), but I analyzed the digital images of the herbarium sheets of S. boissierianum Haussknecht specimens, as available in the digital databases and
Virtual Herbarium.

For a better understanding of the geographical placement of the original collection sites, I depict their situation on a regional map conform to the geographical reference system "Davis, 1965. Flora of Turkey grid system" of Davis (1965) placed in Eurasian context, with the original toponymical data of the collection sites.

\section{Results and discussion}

\section{Sedum boissierianum Haussknecht ex Froeder- stroem (1932:75)}

\section{Bas.:- Sedum Boissierianum Haussknecht} (1932:75). Type (lectotype here designated):- Turkey, Wilajet Kastambuli: P. Sintenis: Iter Orientale 1892. No. 4359 Sedum Boissierianum Hskn. Paphlagonia. Wilajet Kastambuli. Tossia: in declivibus saxos. Prp. Dikmen. 23.VI determ. Prof. C. Haussknecht: (BUCF! No. 37462; the multibranched specimen at the center upper-left side of the herbarium sheet).

The rest of the plants on this herbarium sheet are here designated isolectotypes. Similarly, the plants on the herbarium sheet P00706340, belonging to the same gathering, are duplicates and are designated here as isolectotypes.

The search of the relevant literature did not reveal any printed text with a description of Haussknecht's $S$. boissierianum Hskn previous to Froederstroem's validating treatment from 1932 which regarded it as a synonym of Sedum rubens. Thus, in the text under $S$. rubens L, Froederstrom (1932:75) literally mentions $S$. boissierianum Hskn. as synonym to $S$. rubens L. ("S. boissierianum Hausskn. In herb."). As a caption to Figures 608-614 in (Froederstrom 1932:76), he gives as synonym for $S$. rubens $\mathrm{L}$ (S. bois, from Armenia turc. Erzingham, (sic!) Sintenis 1889, Herb Lund)

Examination of the original herbarium sheet used by Froederstroem as basis for his description and drawings of $S$. boissierianum Hskn. 


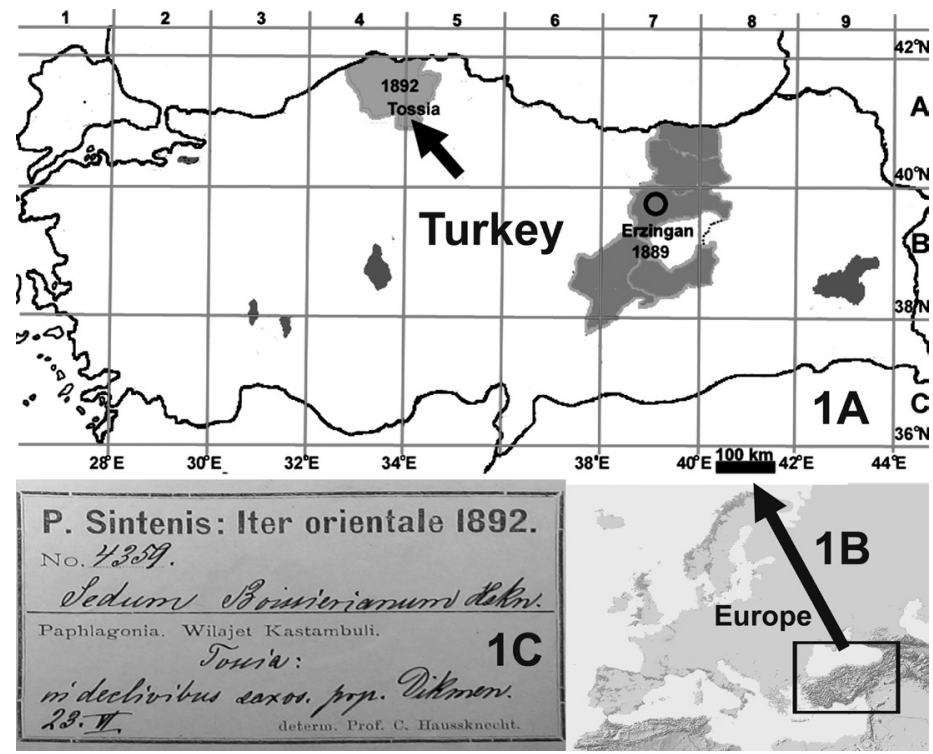

Figure 1 A: Schematic map of Turkey in the grid system of Davis 1973 with the vilayets visited by Sintenis in his 1889 and 1892 trips and the collection sites of the Original material; Erzingan marked by the open circle and Tossia marked with the arrow.

B: Schematic situation of the map in Eurasian context C: Original label of the BUCF 3716 herbarium sheet with the gathering P.Sintenis: Iter Orientale 1892. No. 4359

(LD177072) revealed several interesting facts. The sheet bears two labels, the original one printed with: "P. Sintenis: Iter orientale 1889. No. 1275. Armenia turcica. Det. Dr. O.Stapf" and two different handwritings in different inks. The oldest inscription reads: "Sedum rubens L. Erzinghan; Sepikondagh. 5.vii.".

An additional handwriting in a different shade of black ink is a correction to the first identification; the later author put the specific epithet "rubens" in brackets and added on top of it "S. Boissierianum Hskn. t. Hskn.1893.".

This label also bears an oblique stamp in dark blue-gray ink reading "HERBARIUM P. SINTENIS". A second label (a correction slip) was affixed above the original one and reads "Sedum hispanicum L. var.? Det. Harald Froderstrom 20.4.1931."

I have also found in the herbarium of the For- estry Institute in Bucharest (BUCF) another herbarium sheet from a later gathering made by P. Sintenis in 1892 (see Figure 1). The herbarium sheet in BUCF bears the number 37462 handwritten above the original label, and at the top of the sheet the inventory number "Inv. 3716".

The original label (see Figure 1c) is a generic printed label, generally used for the entire lot of specimens collected by Sintenis in his botanical trip(s) bearing the title: "P.Sintenis: Iter Orientale 1892." followed by the gathering number "No. 4359" and the general location of the collection site and the authority who identified the specimens: "Paphlagonia. Wilajet Kastambuli. determ. Prof.C.Haussknecht". The generic, printed label was filled in with the same handwriting as the corrective annotation on the older label LD177072, and reads: "Se- 
dum boissierianum Hskn. Tossia: in declivibus saxos. prp. Dikmen. 23.VI."

The herbarium in Paris $(\mathrm{P})$ houses another herbarium sheet with plants from the same gathering (P00706340) bearing an original label identical to the one on the Sheet in BUCF, accompanied by two more recent labels as follows: a) an older label reading "Herbier de $\mathrm{Ch}$. D'ALLEIZETTE Famille Crassulaceae Nom scientifique Sedum Boissierianum Hskn Origine et habitat Asie Mineure", and b) a newer label printed with: "HERB. MUS. PARIS. Herbier Ch. D'ALLEIZETTE donné en 1941" The sheet also bears a small label printed "TYPE" in red ink on which someone wrote by hand "POSSIBLE".

Since the binomial Sedum boissierianum Hskn is a basionym that initially appeared only as handwritten name on the labels of several herbarium sheets bearing plants collected by P Sintenis, in the last quarter of the 19'th century in the Near East, it did not fulfill as such the mandatory requirements for effective publication as delineated in Article 38.1. of the Melbourne Code (2012), therefore it should have been considered legally an unpublished nomen nudum.

But, in his 1932 revision of the genus $\mathrm{Se}$ dum, Froederstroem unintentionally validated the original name provided by Haussknecht for specimens originating from Near East.

First, Froederstrom (1932 p75) mentions Sedum boissierianum Haussknecht in a list of synonyms under $S$. rubens L ("S. boissierianum Hausskn. in herb.) providing a text description for it and thus fulfilling the formal requirements for validation of Haussknecht's basionym, under Article 38.1 of McNeill et al. (2012).

Furthermore, he both implicitly (in the captions accompanying the diagnostic drawings for specimens of $S$. boissierianum from Erzinghan, Northern Turkey) and explicitly in the synonymies accepted the name and recognized Haussknecht's paternity and priority over the binomial and its validity for the spec- imen depicted in the diagnostic drawings.

The labels on the LD177072 sheet bring light onto the question of how did this taxon end up relegated to synonymy with $S$. rubens (which is clearly a distinct taxon), together with other taxa also sufficiently distinct.

The first striking aspect revealed by the original label is that the LD177072 plants were initially seen and identified by Otto Stapf (who ascribed them to $S$. rubens) and not by Haussknecht. The same label though, bears a later holograph inscription by prof. Haussknecht who put the epithet "rubens" in brackets and wrote "Sedum boissierianum Hsknt, t. Hsknt 1893". Haussknecht has seen the plants only later (in 1893 according to his handwritten mention "t. Hskn 1893.") and it was only in 1893 that Haussknecht corrected the identification ascribing the plants to his taxon $S$. boissierianum Hskn. This shows that the LD177072 sheet was seen by Haussknecht only in 1893 despite being collected by Sintenis in 1889, 3 years prior to the specimen collected in Tossia/ Kastambuli/Paphlagonia and labeled " $P$. Sintenis: Iter Orientale 1892. No. 4359" that is housed BUCF.

Moreover, this suggests that the LD177072 specimen was not identified by Haussknecht as $S$. boissierianum prior to the specimens collected by Sintenis in 1892 in Tossia - which were labeled ab initio as $S$. boissierianum by Haussknecht, in his own handwriting, but, quite probably, at a later moment. These facts strongly indicate that the LD177072 specimen, although original material, seen and identified by Haussknecht, was most probably not the first specimen named $S$. boissierianum by Haussknecht.

This also indubitably proofs that by 1893 the basionym $S$. boissierianum had already been assigned by Haussknecht to some Sedum specimens collected by P. Sintenis in Northern Turkey.

My hypothesis is that the specimens collected by Sintenis around Tossia were the first specimens named $S$. boissierianum by Hauss- 
knecht after P. Sintenis returned from his 1892 trip to Anatolia, and that it was this discovery that prompted Haussknecht in 1893 to (re)examine the LD177072 specimens which were already seen and identified by Otto Stapf - who had initially assigned them to $S$. rubens.

Therefore, I think another specimen should be chosen as lectotype for this binomial. Consequently, I decided to choose the specimen on the herbarium sheet with inventory number inv3716 housed in BUCF as lectotype and the duplicates on P00706340 as isolectotypes.

Another important aspect advocated by the labels on the LD177072 specimen is that Froederstroem initially added a correction slip ascribing the plants to an unknown variety under $S$. hispanicum and probably later on Froederstroem was induced to believe that $S$. boissierianum was a synonym of $S$. rubens $\mathrm{L}$ by Stapf's identification that directly suggested this synonymy. My belief is that Froederstroem adopted the idea after 1931 from the label and propagated in his 1932 work probably ignoring the androecial differences between S. hispanicum and S. rubens, or considering that haplostemony in Sedum is not such a distinctive taxonomic character as previously thought.

The collection places for the types chosen are situated both in Northern Anatolia, at a distance of less than $500 \mathrm{Km}$ of the collection site of the plant on LD177072 sheet and are depicted in Figure 1a, b on a schematical map of the present-day Turkey with the grid system of Davis (1976), placed in Eurasian context.

\section{Conclusions}

Albeit Froederstroem sinonymized S. boissierianum Hsknt with Sedum rubens L, he clearly recognized Haussknecht's paternity and priority over the binomial and its validity for the specimen depicted in the diagnostic drawings. The specimens on the herbarium sheet in LD177072 were initially examined and iden-

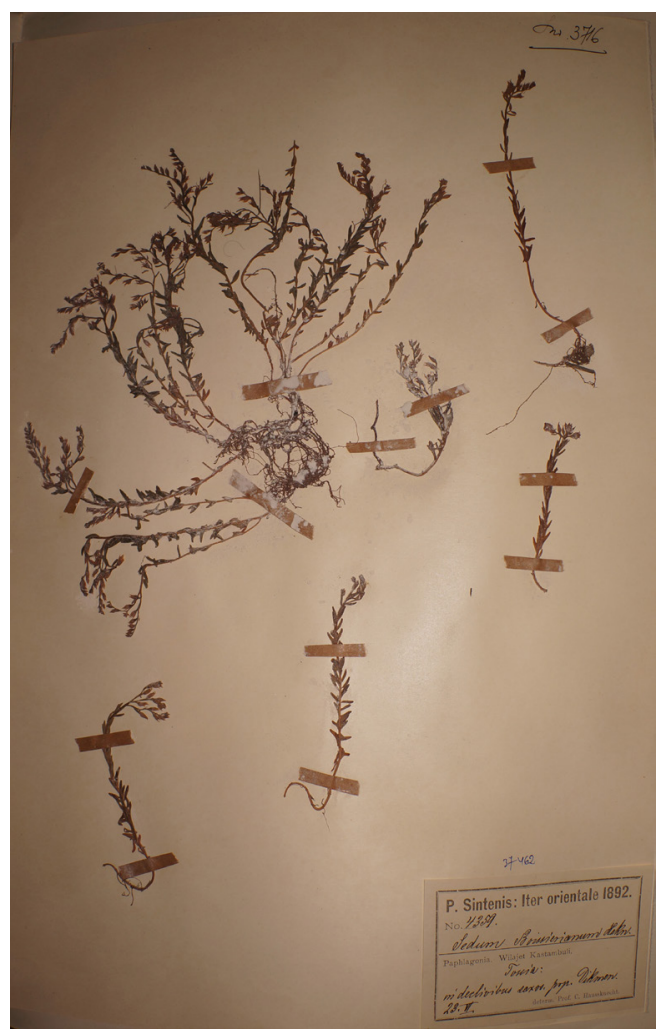

Figure 2 Herbarium sheet housed at BUCF with the gathering P. Sintenis: Iter Orientale 1892. No. 4359

tified by Otto Stapf who ascribed the plants to $S$. rubens, and were only subsequently examined by Haussknecht who assigned them to $S$. boissierianum only in 1893. This fact shows that the LD177072 specimen, despite being an earlier gathering, was only seen in 1893 by Haussknecht, with the obvious implication the plants on this sheet were not the first to bear the binomial S. boissierianum Hskn.

This also indubitably proofs that by 1893 the basionym $S$. boissierianum had already been assigned by Hsknt to some Sedum specimens collected by P. Sintenis in Northern Turkey.

The specimens on LD177072 were clearly NOT named by Haussknecht $S$. boissierianum before the specimens collected by Sintenis around Tossia and labeled "P. Sintenis: Iter 
Orientale 1892. No. 4359" and I believe that the latter were the first specimens to bear this basyonim.

Considering the above-mentioned arguments I have chosen the specimen on the herbarium sheet with inventory number 3716 housed in BUCF to be designated as lectotype and the duplicates on P00706340 as isolectotypes.

The present research also reveals that Froederstroem initially (in 1931) considered the LD177072 specimens a probable variant of S. hispanicum, but later changed his mind adopting Stapf's view that the plants belong to $S$. rubens; this explaining the placement of $S$. boissierianum Hsknt in synonymy with $S$. rubens $\mathrm{L}$.

\section{Acknowledgements}

Thanks are due to Dr. H. Witzell and Mr. Patrik Froden, for their help concerning the LD herbarium specimens, to Mr. Dragoș Panaitescu for the help with geographical data, to Ms. Marilena Niculae for helpful comments on the manuscript and to Ms. Aura N. Bârcă for the help with the artwork.

\section{References}

Baytop A., 2010. Plant collectors in Anatolia (Turkey).
Phytologia Balcanica 16(2): 187-213

Cullen J., 1963. The Turkish collections of Paul Sintenis. Notes from the Royal Botanical Garden Edinburgh 25: 31-39.

Davis P.H., 1965. Turkish vilayets and grid system. In: Davis, P.H. (ed.), Flora of Turkey and the East Aegean Islands 1. Edinburgh University Press, Edinburgh, pp. 10-12.

Froederstroem H., 1932. The genus Sedum L 2. Acta Horti Gothoburgensis. 6:1931 (Suppl 1932: 1-111).

Hart t' H., 1991. Evolution and classification of the European Sedum. Flora Mediteranea 1: 31-61

IPNI International plant name index. Web: http://www. ipni.org. Accessed: 02.2015.

Linnaeus C., 1753. Species Plantarum ed. 1 Laurentii Salvii, Stockholm, 560 p.

Linnaeus C., 1754. Genera Plantarum. Ed 5 Laurentii Salvii Stockholm, 522 p.

McNeill J.,Barrie F. R., Buck W.R., Demoulin V., Greuter W, Hawksworth D. L., Herendeen P.S., Knapp S., Marhold K., Prado J., Prud'homme van Reine W. F., Smith G.F., Wiersema J. H., Turland N.J., 2012. International Code of Nomenclature for algae, fungi, and plants (Melbourne Code). Regnum Vegetabile 154. Koeltz Scientific Books.

Niculae M., Bârcă V., 2005. Preliminary data regarding the distribution of the species Sedum hispanicum L (Crassulaceae) in Romanian Southern Carpathians, Contribuții Botanice. Grădina Botanică 'Alexandru Borza' Cluj-Napoca XL: 35-42.

Niculae M., Bârcă V., 2006. Preliminary data regarding the distribution of the species Sedum annuum L (Crassulaceae) in Romanian Southern Carpathians. Contribuții Botanice, Grădina Botanică 'Alexandru Borza' Cluj-Napoca XLI: 33-40

Thiers B., 2012. Index Herbariorum: A global directory of public herbaria and associated staff. Web: http://sweetgum.nybg.org/ih/. Accessed: 10.03.2015.

Vegter I.H., 1986. Index Herbariorum, Part II(6): Collectors S. - Regnum Veget., 114. 